\title{
Revisioning The Detective Canon: A Study of $A$ Slight Trick Of The Mind and The Final Solution
}

\author{
Dr. Abdul Mohammed Ali Jinnah ${ }^{1}$, R. Lakshmi Priya ${ }^{2}$ \\ \{abdul.m.jinnah@gmail.com¹, tharikapriya@gmail.com² \\ ${ }^{1}$ Affiliated to Bharatidasan University, Associate Professor of English, Jamal Mohamed College, Trichy. \\ ${ }^{2}$ Affiliated to Bharatidasan University, PhD Research Scholar,Bishop Heber College,Trichy, Tamil Nadu
}

\begin{abstract}
Postmodernism, when it comes to literary landscapes, has opened up various possibilities for experimentation. One such style of postmodern experimentation writing is pastiche and parody; though both these styles have their inception in the modernist period, there is a serious shift in the ideology of people during contemporary times, and authors of this zeitgeist use the same to create a writing that synergies with the mindset of people. The works taken for interogation apply postmodern principles of writing in detective genre, primarily focussing on the Sherlock Holmesian character in his dotage. These reworkings are not just genre-bending but also reject the meta-recit, thereby creating a subversive narrative.
\end{abstract}

Keywords: Anti-Establishment Literature, Anti-Detective Fiction, Intertextuality, Sherlock Holmes, Zeitgeist.

\section{Introduction}

"Post modernism as an ideology, however, is better grasped as a symptom of the deeper structural changes in our society and its culture as a whole, or in other words, in the mode of production." - Fredric Jameson.

The rejection of méta récit in Lyotardian terms is the epistemology of Postmodern culture. The grand narratives are not constrained to religion, science and politics; rather the terminology expands to art, particularly to literature. The skepticism towards canonical work of arts, the interrogation of the established order, the questioning attitude in the differentiation of high-brow and low-brow literature are the trademarks of a postmodern attitude.

\section{Discussion}

The detective fiction is one among those many genres which have long been considered to be catering to mass-market than to elite audiences. Over a period of time, detective fiction has broken this stereotype by its sheer synchrony. The active participation of literary writers like Charles Dickens, Mark Twain and O. Henry; and to contemporary writers like Italo Calvino in If On a Winter's Night a traveler, Umberto Eco in Name of the Rose, Haruki Murakami in Wild Sheep Chase, Jose Saramago in All the names and Patrick Modiano in Missing Person proves the exuberance of this genre. Detective fiction is also subjected to numerous 
critical analyses from its origin. Writers of detective fiction like Raymond Chandler in The Simple Art of Murder and S. S. Van Dine's Twenty Rules for Writing Detective stories are examples of the same. The structure of detective fiction was considered fixed and any break in the frame work was heresy according to many earlier critics. Detective fiction was supposed to possess inherently in its structure, certain rules, as time and again insisted by critics like T. S. Eliot, Van Dine among others ; such statements emphasised is the seriousness of the genre. The postmodernists, however, ponder over the reversal of these rules. The many examples of aberration, disfiguration, reversal, dismantling and breakage in the rules mentioned by critics of detective fiction, has led to a unique genre, the Anti - detective fiction. Though postmodern writers claim it to be postmodern mystery, it is mandatory to observe that this break in tradition has existed even from the time of its conception. The incorporation of antithetical principles to the rules predominated the anti - detective fiction. The anti - detective fiction saw to it that every commandment of writing a detective fiction was inverted thus shocking the readers, ridiculing the critics and caricaturing the genre. As an example, the whole world of detective fiction, concentrated on the crime. The postmodern writers inverted this logic by writing a detective track bereft of crime. In a book such as Cosmos by Witold Gombrowicz, there is no crime, yet the assumed detective operates on the seminal detective quest of looking for clues. Similarly Paul Auster creates a detective story sans any crime in his New York Trilogy. The conventional theorists of detective fiction, be it Ronald Knox when he stated that, "All supernatural or preternatural agencies are ruled out as a matter of course" would have simply rejected such postmodern attempts as been against the very grain of the genre. Van Dine's statement quoted below is anathema to the contemporary writers of anti-detective fiction:

The problem of the crime must be solved by strictly naturalistic means. Such methods for learning the truth as slate-writing, ouija-boards, mind-reading, spiritualistic seances, crystal-gazing, and the like, are taboo. A reader has a chance when matching his wits with a rationalistic detective, but if he must compete with the world of spirits and go chasing about the fourth dimension of metaphysics, he is defeated ab initio. (Twenty Rules for writing a detective fiction, Van Dine) [1]

This rule is broken by Haruki Murakami in many books, including Kafka on the Shore, Wild Sheep Chase and Wind Up Bird chronicles. Detective fiction from the time of its conception bore in it numerous elements of intertextuality. The first acclaimed short story, by Edgar Allen Poe, featuring Auguste Dupin, was ridiculed by Sherlock Holmes. Despite being inspired by Auguste Dupin, Sherlock Holmes simply rejects him and his other precursors, stating he is unique and extraordinary. The Holmesian rejection of Auguste Dupin as, "Now, in my opinion, Dupin was a very inferior fellow". In Harold Bloom's terminology The Anxiety of Influence that Holmes faces, and in order to not be judged as one among the stock leads him to rejection of Lecoq and Dupin. Sherlock Holmes sniffed sardonically. "Lecoq was a miserable bungler," he said, in an angry voice; "he had only one thing to recommend him, and that was his energy. That book made me positively ill. (Study in scarlet, 11) [2]

This is not the only example of Arthur Conan Doyle employing intertextuality. The most cliched The Game is Afoot, is a phrase borrowed from King Henry IV Part I, 1597, written by Shakespeare, which was conceived as "Before the game is afoot, thou still let'st slip."[3] Similarly in the book, The Sherlock Holmes Book the writers suggest at least 10 different inspirations for various characters including Holmes himself. Hence it would not be ambivalent to say that it was Arthur Conan Doyle who begun the great tradition of intertextuality in detec- 
tive fiction. Even during the time of Doyle, there had been numerous reworkings of Sherlock Holmes stories, one example is that of Ellery Queen, titled The Misadventures of Sherlock Holmes which is an anthology written by various detective and non - detective fiction writers who were contemporary to Doyle and his immediate successors. Few of these stories were even read by Doyle himself. These stories venture in creating, a down to earth hero, who is unlike Holmes in his demeanour. Every aspect of Holmes' life is ridiculed and caricatured in these stories. In a short story, Holmlock Shears arrives too late by Maurice Leblanc, he uses the opportunity to give it back to Holmes, after Doyle ridiculed the character created by him, Lecoq. The story features Lecoq, who steals the watch of Sherlock Holmes himself.

"He must have taken your watch! Oh, this is too good! Holmlock Shears's watch spirited away by Arsene Lupin! Oh, this is too funny for words!" (Queen, Ellery ed. The misadventures of Sherlock Holmes.) [4]

These stories exemplify that Sherlock Holmes, though created as a thinking machine, the brilliant robot and he himself states that, "I am a brain, Watson. Rest of me is a mere appendix" is brought down from his stature, his more than human image is shattered into pieces by these writers. The fandom of Sherlock Holmes is so popular that even after his death, the revisionist narratives of Sherlock Holmes continues. In contemporary times, writers of postmodern ideology reject the canonical image of Sherlock Holmes, the master of detection and deduction and instead build a mirage of Sherlock Holmes filling up the lacunae left by Conan Doyle in his original conception. Many of the postmodern reworkings, similar to Ellery Queen's compilation focus on demeaning the character of Holmes. The writers involved in the process of recreating concentrate primarily the 'great hiatus' that is, the gap in the narrative when Holmes goes missing after Reichenbach Falls incident and lasting for seven years till the publication of The Empty House. Similarly the old age of Sherlock Holmes and his last mystery are treated with similar curiosity by writers who rework the Holmesian Canon. Chrono-synclastic infundibulum, the term that is used to represent the merge between spatiality and temporality is the basis for many pastiches and parodies that are made on Sherlock Holmes. The writers condense the past infringements and amalgamate it with present day scenario. Harold Bloom when explaining the 'Anxiety of Influence', differentiates it into various types and the process of Kenosis, where a movement towards discontinuity with the precursor is seen as one of the major types.

\section{Literature Review}

This research paper will concentrate on reworking of Sherlock Holmes, based on Bloom's concept of Kenosis pertaining to the books, A Slight Trick of the Mind by Mitch Cullin and The Final Solution by Michael Chabon. The commonality of both the novels lie in the fact that it concentrates on the old age of Sherlock Holmes, though there is no mention of the protagonist as Sherlock Holmes, in the book The Final Solution, there are numerous clues for the readers to understand that the character is based on Sherlock Holmes.

The primary clue in The Final Solution is the beekeeping which is also the occupation that old Holmes takes up in A Slight Trick of the Mind. The readers of Sherlock Holmes are aware of the fact that in the short story The Last Bow, Conan Doyle himself states that Sherlock Holmes after his retirement not merely starts to rear bees, but also writes a book on it. 
But you have retired, Holmes. We heard of you as living the life of a hermit among your bees and your books in a small farm upon the South Downs.' (The Last Bow, Conan Doyle) [2]

Similarly both the characters of The Final Solution and A Slight Trick of the Mind are not merely bee keepers but were also detectives in their past. The Holmes in The Final Solution, remembers episodes of solving the ingenious criminals during his detective days, similarly The Holmes of A Slight Trick of the Mind, seems to remember the solution of most of his cases, but is haunted by his retirement and the reason leading to it. Unlike the young Sherlock Holmes, who was active, and portrayed as a super hero embodiment of the detective, Sherlock Holmes in his old age suffers from ailments like memory loss, knee pain and severe mental depression. The unemotional character Holmes, is perceived as an emotional being in both the novels; he is connected to young boys in both novels and is concerned about them . Sherlock Holmes even goes to the extent of taking care of the boy, which portrays the emotional and more humane side of Sherlock Holmes as opposed to the character arc created by Doyle.

Both the novels are detective narratives, The Final Solution dealing with a dumb Jewish boy, who is attached only to his pet parrot which keeps reciting German numbers. In the novel, when the parrot is lost, and a man dies, Sherlock Holmes resumes from his retirement and starts to aid the boy in finding his parrot. Similarly in the novel, A Slight Trick of the mind Sherlock Holmes, who was a detective in his past, becomes so close to the young boy of his caretaker. The closeness leads Holmes to recollect his past and recount the incidents to him. When he understands his inability to remember the past, it frustrates him and creates severe mental depression; the novel focuses on Holmes various ways to evoke his memory. The character of Holmes in the novels is pathetic, forgetful, sick and frail. Yet, there is a huge impact of humaneness that was missing in the original stories, as the canonical Holmes was a person who completely rejected any contact with human being as in terms of relationship or friendship.

In the novel, The Final Solution, despite finding the parrot, Holmes is never able to break the code as to the numbers the parrot recites; similarly in the novel, A Slight Trick of the Mind, the memory of his last case, brings him to the recollection that he left it unsolved and after twenty years he tries to recollect and solve the case, which could bring no benefit or even a semblance of success. Both the novels create a tragic outlook into the character of Sherlock Holmes and humanises him, the Sherlockian traits of bohemia, quirkiness and rejection of human emotions are shattered in these creations thus making Sherlock Holmes a man of emotion and brings him down from his stature. The depiction of the fictional character Sherlock Holmes as old, pertains to the use of Kenosis, as the character is both the extension of original and yet at the same time is a discontinuity of the precursor; in the sense the creation of Holmes is a mirror image and yet he is the disruption of the original. The brave and strong Holmes is replaced by man who fears for his death and is worried about his ailment and forgetfulness.

He did not fear death exactly, but he had evaded it for so many years that it had come to seem formidable simply by virtue of that long act of evasion. In particular he feared dying in some undignified way, on the jakes or with his face in the porridge." [5]

In A Slight Trick of the Mind, Sherlock Holmes when confused because of his old age and memory loss, thinks about his own death but also negates it stating that he has seen numerous 
deaths in his life from criminals, to victims, to his friend, family and lately his brother Mycroft.

But Holmes was well acquainted with death's unwelcome arrival—or at least he wished to believe so - and hardly did its sudden visitations surprise him anymore. [6]

\section{Conclusion}

The writers of postmodernist narratives use numerous techniques for experimentation; pastiche being one among them. The reworking of Sherlock Holmes, dealing the characteristic traits of the character is an influence of canonical stories that are inverted, revised, revisited and debunked by these writers. The strong character Sherlock Holmes who was given a super human stature is shattered in these two novels, bringing him down to earth and recreating him as an embodiment of emotions, love and fear. By doing this, the writers have humanised and reversed the canonical Sherlock Holmes. These not merely provide the reader with an altered version of reality, but also create a familiar story line by changing the existing tropes and thereby creating a newer version of reality.

\section{References}

[1] Dine,Van.:Twenty Rules for writing a Detective Fiction. (1928)

[2] Doyle, Arthur C.: The Penguin Complete Sherlock Holmes. Penguin Group. London (1981)

[3] William, Shakespeare.: The complete works of William Shakespeare. Barnes and Nobles collectible classics: Omnibus edition (2015)

[4] Queen, Ellery (Edited).: The Misadventures of Sherlock Holmes. pp. 185 Little, Brown and Company. Boston e.book (1944)

[5] Chabon, Michael.: The Final Solution: A Story of Detection. pp. 43, Harper Perenial Reprint edition (2005)

[6] Cullin, Mitch.: A Slight Trick of the Mind. pp. 347. Anchor; reprint edition (2006) 